\title{
Familial Aggregation of Chiari Malformation: Presentation, Pedigree, and Review of the Literature
}

\author{
Laszlo NAGY, James MOBLEY, Coby RAY \\ Texas Tech University, Health Sciences Center, Texas, USA
}

\section{ABSTRACT}

This article reports the largest familial aggregation of Chiari malformation in a single family to date as reported in the literature. This study is a retrospective case series of a family of whom five individuals have a confirmed case of Chiari malformation and three additional individuals have Chiari signs and symptoms. This contribution further supports the implication of genetics in the transmission of Chiari malformation. The family reported in this study also has a significant incidence of Ehlers-Danlos. Three sisters, including a set of twins, presented with confirmed cases of Chiari malformation and four of the five children of the twin sisters presented with confirmed or suspected Chiari malformation. Of note, the non-twin sister has three children who are unaffected. This report provides further evidence for a shared loci between the Chiari malformation and Ehlers-Danlos.

KEYWORDS: Chiari malformation, Genetics, Pedigrees, Primary chiari

\section{INTRODUCTION}

Chiari Malformation (CM) is typically considered to be the downward herniation of the cerebellar tonsils through the foramen magnum. The basic presentation of symptoms include occipital headaches, balance and coordination issues, and other associated cerebellar signs. This disease process affects both adult and pediatric patient populations, but symptoms vary by age. The presenting symptoms can be quite variable as well. Chiari malformations can be the result of a known etiology or can occur without any known causative factors. The Chiari that occurs from an unknown etiology is likely the result of a genetically determined small posterior fossa volume.

There is a growing amount of data in the literature supporting a genetic basis for the Chiari malformation. However, familial aggregation in the literature is limited to twins, triplets, and a few cases of two consecutive generations being affected. While multiple projects are underway in the United States to identify a gene that can be specifically linked to the Chiari Malformation, none has yet elucidated the gene. One of the primary goals of the presentation of this family is to further illuminate the likely mode of genetic inheritance based on the large pedigree that is demonstrated below.

\section{CASE REPORT}

This study is a case report of a patient's family of whom five individuals had a confirmed case of Chiari malformations and a total of eight were symptomatic (including the 5 confirmed). The incidence of Chiari malformations confirmed by CT scans occurred in two consecutive generations. The symptomatic individuals spanned three generations. The family of this child under our care also has a very large incidence of EhlersDanlos syndrome.

Of the three daughters (III-7, III-8, and III-9) of the individual (II-3), all were radiographically confirmed cases of Chiari I Malformation (Figure 1). These patients lived in rural communities and thus were diagnosed with CT imaging instead of MRI, due to access and funding. However, in all of the patients the diagnosis was clear on the CT images, and was confirmed with $\mathrm{MRI}$ in some. Patient III-8 is the 


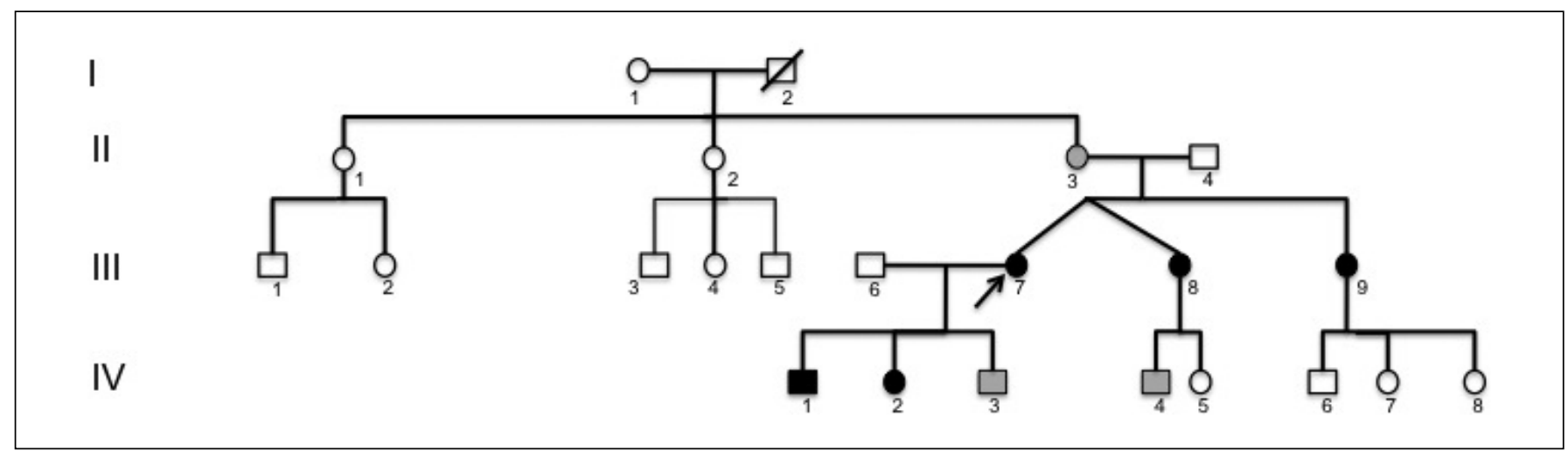

Figure 1: The proband is indicated by the arrow. The confirmed cases of Chiari are represented in black. The individuals affected by Chiari symptoms are shaded gray.

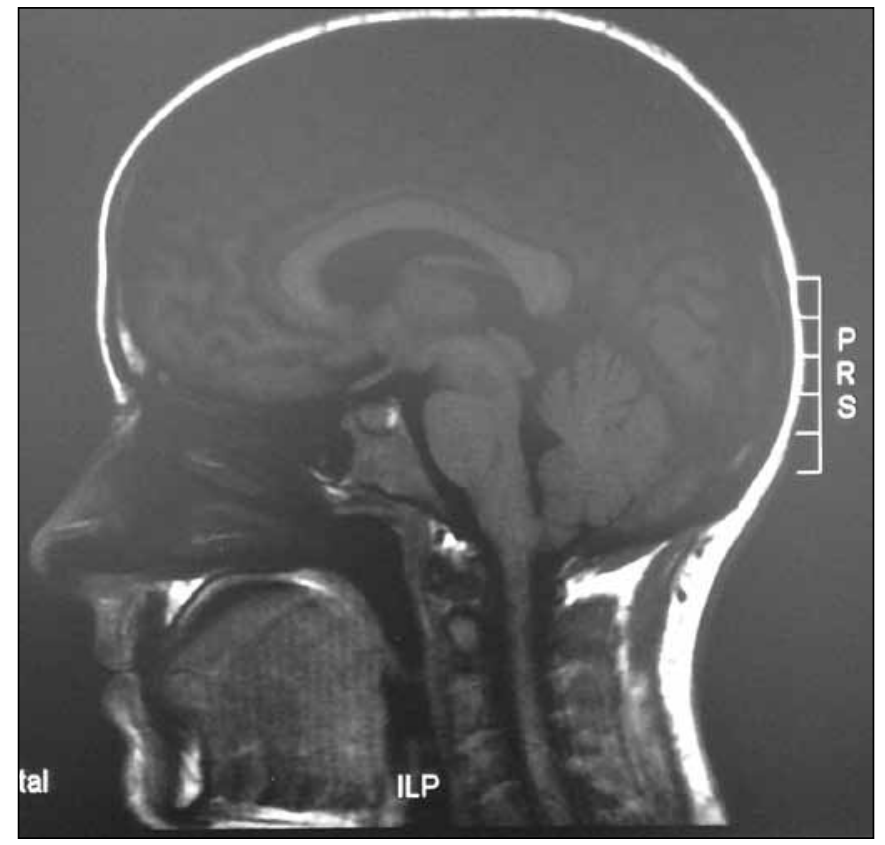

Figure 2: Patient III-8 Chiari 0 displaying a crowded posterior fossa and slight herniation of the cerebellar tonsils in the twinsister of the proband.

only daughter of II-3 not treat for CM (Figure 2). This sister, however, does report Chiari related symptoms. The other sister with a confirmed case of Chiari I Malformation (III-9) has three children (IV-6, IV-7, IV-8) who do not have head CT scans but report frequent headaches. Patient III-7 has three children, two of which have confirmed cases of Chiari (IV-1, IV-2). The third and youngest child (IV-3) is beginning to present with Chiari-related symptoms and will likely undergo CT scan in the future. Of the five confirmed cases, four are females.

Seven patients without radiographic confirmation of a diagnosis of CM complained of persistent signs and symptoms consistent with those of Chiari malformations. To diagnose Chiari based on clinical findings, we used the presence of occipital headaches. These headaches had to be consistently present and worse with straining, coughing, or Valsalva. Other common neurological signs were present in most (Table I). Of the seven individuals reporting signs and symptoms, four of the seven were female. Two-sets of three are siblings including one set of twins. All of these patients presented with severe headaches that occur daily or multiple times a week. Most of the individuals complained of headaches that originated in the occipital region of the head and upper neck. The patients also complain of balance and coordination deficiencies, including reported severities such as consistently stumbling into walls and doorways. They also report falling down often. Patient II-3 reports headaches for as long as she can remember. She states that these headaches "start in the back of her head and move forward to the top of her head." Patient III-8 (Figure 1) reports a headache in the "back of her head" that never goes away," "running into things all the time," frequently falling down, and multiple episodes of syncope. She also reports vision difficulties and chronic pain in the back of her head and neck. Patient IV-3 reports headaches that occur multiple times a week and his parents report he has severe coordination issues. Patient IV-4 reports occipital headaches that occur every day. He has also been diagnosed with Human Growth Hormone deficiency and Ehlers-Danlos Syndrome.

Other family members have been diagnosed or have symptoms consistent with Ehlers-Danlos Syndrome. In addition to IV4, his mother (III-8) has been diagnosed with Ehlers-Danlos Syndrome. The family reports that individuals I-2, III-1, III-2, III-3, III-4, III-5, and III-9 are all suspected of having EhlersDanlos Syndrome due to symptoms of hyperextensiveness.

\section{DISCUSSION}

Overcrowding of the posterior fossa or a normal amount of substance in an unusually small posterior fossa is likely the culprit of the downward displacement of the cerebellum (2, $5,15,22,23,28,30,31,34,39,42,45,47)$. Many of the symptoms of Chiari may be the result of obstructed CSF flow (7) and the development of scar tissue of the cerebellar tonsils and the compression of the cerebellum and spinal cord (3, 7 , 27).

Chiari malformation is likely the result of a small posterior fossa and thus the embryonic development of the posterior 


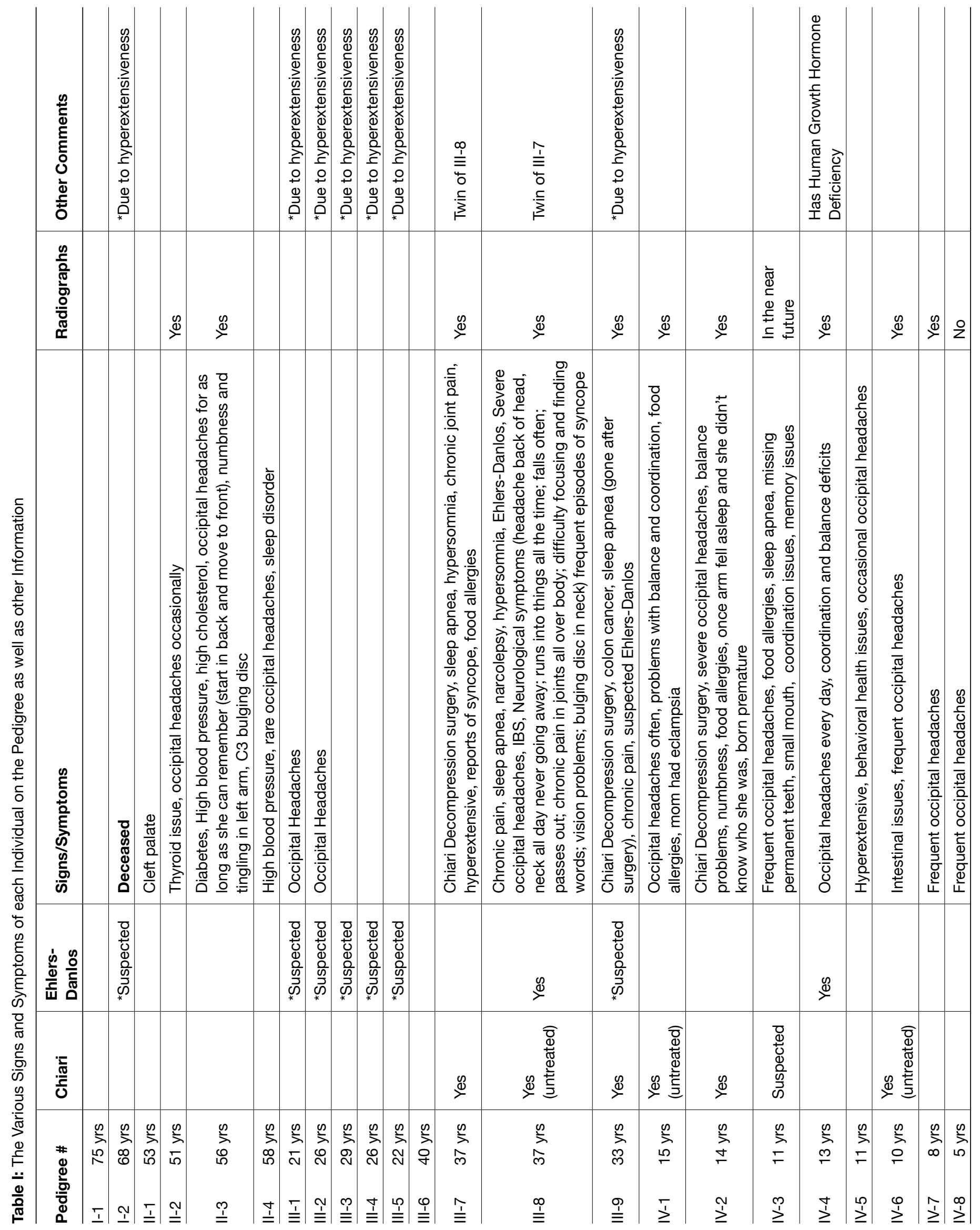


fossa may be the link between genetics and phenotype ( 7 , $24,30,43)$. Boyles reported that the volume of the posterior fossa was "highly heritable" (7). Embryologically, the Chiari malformation has been described as a mesodermal deficiency (30) and as a neuroectodermal failure (4, 26, 27). Gripp, however, proposes that displacement of the cerebellar tonsils may be due to osseous and cartilaginous abnormalities instead of being the result of embryological disturbances (19). Other authors have offered that Chiari type II, which is thought to be associated with neural tube defects, also shows the potential to have a genetic basis of inheritance $(12,16,19,48)$. It is also possible that having a small posterior fossa is the phenotype of those with a genetic predisposition to developing the Chiari malformation. This may at least be offered as an explanation of the varied phenotypic presentations of Chiari patients (24).

In the largest study of cases with familial aggregation of Chiari, Milhorat demonstrated that while still seemingly sporadic (1, 28), the Chiari malformation does seem to have the potential for genetic transmission. Milhorat's study showed a significantly increased incidence in women (28). He demonstrated that out of 364 confirmed cases of Chiari Malformation, 275 of them were female (75\%) (28). Of these reported cases, he reported that $12 \%$ self-reported a family history of Chiari (28). Milhorat reported twenty-one pedigrees that showed inheritance patterns indicative of autosomal dominant or recessive inheritance (28). The $75 \%$ incidence of females remained true in the population that reported familial aggregation (28). He concluded from his study "the demonstration of familial inheritance suggests a genetic component of transmission" (28). This large disparity of female cases to male cases has also been reported elsewhere in the literature as well $(21,30$, 33).

The pedigree in this report fully supports the female predominance reported previously in the literature. Of the affected members in the family presented here, four of the five confirmed cases of Chiari were females. Also in agreement with these previously reported values is the fact that four of the seven individuals presenting with signs and symptoms of Chiari are females. These findings are also consistent with the current theory that there is a higher incidence of Ehlers-Danlos in females despite its known inheritance pattern of autosomal dominant $(11,27)$. No mechanism of inheritance has been discovered to explain this finding (11).

Milhorat concluded that in families with familial aggregation of Chiaris, other members did seem to show an abnormal incidence of displaced cerebellar tonsils through the foramen magnum (27). Cavender points out in their study that based on "extrapolation from a study conducted by Barkovich, et al. estimates the incidence of tonsillar ectopia to be approximately $3.5 \% "(3,12)$. This is extremely significant considering the percentage of family members afflicted with Chiari malformations in the family to be presented in this study. Specifically, 45 percent of individuals in the two generations of family members are confirmed cases and 64 percent are affected cases.

The literature shows a preponderance of reports of twins and triplets that display a familial aggregation. In 1990,
Herman reported what appears to be the first instance of Chiari malformation displayed in multiple individuals in the same family when he reported two siblings with the disease (20). This is highly unlikely to be the first case of familial aggregation, but does seem to be the first time it was reported in the literature. Atkinson et al. reported monozygotic twin sisters and the daughter of one of the sisters (1). Stovner also reported monozygotic twins and their mother as having Chiari Type I $(38,40,41)$. Cavender reported a family in which monozygotic triplets all had confirmed cases of Chiari. The triplets in Cavender's report also had syringomyelia. Cavender and Schmidt went on to conclude that because of the $100 \%$ concordance in the triplets he reported, a genetic basis for Chiari is "highly suggested" (12). Weisfeld et al. reported three sisters with Chiari malformation (49). Speer et al. reports two sets of monozygotic twins with Chiari malformations (37). Speer et al. also reported that there appears to be a higher incidence in monozygotic twins than in dizygotic twins (36). Multiple other studies showed familial aggregation of Chiari (9, $13,14,17,19,25,29,35,42,44,46,50-52)$.

In this article, the patient's family having a large incidence of Ehlers-Danlos Syndrome also points to a correlation between the two diseases. Previous authors have proposed mechanisms for this relationship. The incidence of EhlersDanlos is reported to be one per 5.000 to 10,000 individuals and the incidence of CM-I is estimated at one per 1.000 to 5.000 individuals (27). The likelihood of both diseases coincidentally appearing in the same family based on the reported incidence rate in the population is one out of 10.000 .000 (27). Thus it is reasonable to assume that there is a genetic linkage to these two diseases. The family pedigree shows an autosomal dominant inheritance pattern, especially when symptomatic patients without radiological confirmation are considered. This also follows the reasoning supporting the genetic linkage with Ehlers-Danlos which is also generally accepted to be autosomal dominant (27). Milhorat, et al., explored a similar association of hereditary disorders of connective tissue with CM-I by prospectively studying 2813 patients with CM-I. That study reported that 139 of 2813 patients reportedly had both a hereditary disorder of connective tissue and CM-I. Of the 139 , only 44 had familial inheritance and of the 44 only 20 had greater than one relative with CM-I and even less (17) had more than one relative with a hereditary disorder of connective tissue (27). This makes this presentation of such a large pedigree significant.

The proposed mode of genetic transmission of Chiari is somewhat varied in the literature, and the large family represented by this study allows for a more substantial proposal of transmission. Mendelian transmission has been reported as autosomal dominant inheritance with decreased penetrance or autosomal recessive $(6-8,10,18,19,25,28$, $32,52)$. Milhorat, in the largest pedigree analysis of Chiari families, reported autosomal dominant as those with male-tomale vertical transmission and autosomal recessive as those without an affected parent (28). Petraglia also reports that the propensity of Chiari malformations to accompany other genetic diseases suggests a genetic mode of transmission $(19,24,25,32)$. 
This article presents the largest-reported familial aggregation of radiograph confirmed cases of Chiari Malformation. In addition to this, a total of eight patients presented with signs and symptoms consistent with Chiari Malformations. This is the largest incidence of familial aggregation of Chiari presented to date in the literature. As larger pedigrees, like the one presented here, are presented in the literature, greater insight into the inheritance pattern and mode of transmission can be gained. A family with such a large predominance also provides an excellent candidate family for further genetic analysis - which is currently in progress. Boyles proposes Fibrillin-1 (FBN1) on chromosome 15 as a plausible candidate gene for $\mathrm{CMI}$ due to its known role in related genetic disorders (7). While further exploration of this gene specifically is outside the scope of this case series, the family presented in this study could potentially be an excellent source of genetic analysis. In addition to this, the family provides an excellent model for considering the potential of a genetic link between EDS and CM-I.

A primary implication of understanding the genetic basis of Chiari is that clinicians should have a significantly increased index of suspicion in patients with a family history of Chiari. Patients who are likely to have inherited a smaller posterior fossa are seemingly at a much higher risk of suffering from signs and symptoms of Chiari malformations. Even if the cerebellar tonsils are not actually herniated through the foramen magnum, the patient could be suffering from the effects of a crowded posterior fossa. It is likely the reduced size of the posterior fossa, regardless of herniation, that causes the exacerbation of symptoms with activities such as Valsalva and coughing. While, research is needed to confirm, it seems reasonable to these authors to accept that these patients would benefit from posterior fossa decompression.

\section{CONCLUSION}

Based on a search of the literature, no author has previously presented a family with more than three confirmed cases of Chiari. The family presented in this study contributes a significant step toward proving the genetic basis of Chiari malformations. This article provides a solid foundation for further genetic analysis of the reported family. This pedigree demonstrates a high likelihood of genetic locus homogeneity between Chiari and Ehlers-Danlos Syndrome.

The pedigree also demonstrates that clinicians treating patients with neurological signs and symptoms should have a significantly increased index of suspicion for Chiari when a family member has also been diagnosed with Chiari. This should include exploring the possibility of a crowded posterior fossa without cerebellar herniation. Further exploration is needed to identify whether or not these patients would benefit from a decompressive craniectomy.

\section{REFERENCES}

1. Atkinson JL, Kokmen E, Miller GM: Evidence of posterior fossa hypoplasia in the familial variant of adult Chiari I malformation: Case report. Neurosurgery 42(2):401-403; discussion 404,1988
2. Badie B, Mendoza D, Batzdorf U: Posterior fossa volume and response to suboccipital decompression in patients with Chiari I malformation. Neurosurgery 37(2):214-218, 1995

3. Barkovich AJ, Wippold FJ, Sherman JL, Citrin CM: Significance of cerebellar tonsillar position on MR. AJNR Am J Neuroradiol 7(5):795-799, 1986

4. Barry A, Patten BM, Stewart BH: Possible factors in the development of the Arnold-Chiari malformation. J Neurosurg 14(3):285-301, 1957

5. Batzdorf $\mathrm{U}$ : Treatment of syringomyelia associated with Chiari I Malformation. In: Tamaki T, Batzdorf U, Nagashima T, (eds). Syringomyelia, Current Concepts in Pathogenesis and Management. Tokyo: Springer-Verlag, 2001:121-135

6. Bentley SJ, Campbell MJ, Kaufmann P: Familial syringomyelia. J Neurol Neurosurg Psychiatry 38(4):346-349, 1975

7. Boyles AL, Enterline DS, Hammock PH, Siegel DG, Slifer SH, Mehltretter L, Gilbert JR, Hu-Lince D, Stephan D, Batzdorf U, Benzel E, Ellenbogen R, Green BA, Kula R, Menezes A, Mueller D, Oro' JJ, Iskandar BJ, George TM, Milhorat TH, Speer MC: Phenotypic definition of Chiari type I malformation coupled with high-density SNP genome screen shows significant evidence for linkage to regions on chromosomes 9 and 15. Am J Med Genet A 140(24):2776-2785,2006

8. Busis NA, Hochberg FH: Familial syringomyelia. J Neurol Neurosurg Psychiatry 48(9):936-938, 1985

9. Caldemeyer KS, BoazJC, WappnerRS, Moran CC, Smith RR, Quets JP: Chiari I malformation: Association with hypophosphatemic rickets and MR imaging appearance. Radiology 195(3):733-738, 1995

10. Caraceni T, Giovannini P: Familial syringomyelia: A report of four cases. Arch Psychiatr Nervenkr 224(4):331-340, 1977

11. Castori M, Camerota F, Celletti C, Grammatico P, Padua L: Ehlers: Danlos syndrome hypermobility type and the excess of affected females: Possible mechanisms and perspectives. Am J Med Genet Part A 152: 2406-2408, 2010

12. Cavender RK, Schmidt JH 3rd: Tonsillar ectopia and Chiari malformations: Monozygotic triplets. Case report. J Neurosurg 82(3):497-500,1995

13. Colombo A, Cislaghi MG: Familial syringomyelia: Case report and review of the literature. Ital J Neurol Sci 14(9):637-639, 1993

14. Coria F, Quintana F, Rebollo M, Combarros O, Berciano J: Occipital dysplasia and Chiari type I deformity in a family. Clinical and radiological study of three generations. J Neurol Sci 62(13):147-158, 1983

15. Friede RL, Roessmann U: Chronic tonsillar herniation: An attempt at classifying chronic herniations at the foramen magnum. Acta Neuropathol 34(3):219-235, 1976

16. Gardner E, O'Rahilly R, Prolo D: The Dandy-Walker and ArnoldChiari malformations. Clinical, developmental, and teratological considerations. Arch Neurol 32(6):393-407,1975

17. George S, Page AB: Familial Arnold-Chiari Type I malformation. Eye (Lond) 20(3):400-402, 2006

18. Giménez-Roldán S, Benito $C$, Mateo D: Familial communicating syringomyelia. J Neurol Sci 36(1):135-146, 1978

19. Gripp KW, Scott Cl Jr, Nicholson L, Magram G, Grissom LE: Chiari malformation and tonsillar ectopia in twin brothers and father with autosomal dominant spondylo-epiphyseal dysplasia tarda. Skeletal Radiol 26(2):131-133, 1997

20. Herman MD, Cheek WR, Storrs BB: Two siblings with the Chiari malformation. Pediatr Neurosurg 16(3):183-184, 1990-1991 
Nagy L. et al: Familial Aggregation of Chiari Malformation

21. Levy WJ, Mason L, Hahn JF: Chiari malformation presenting in adults: A surgical experience in 127 cases. Neurosurgery 12(4):377-390, 1983

22. Marin-Padilla M: Notochordal-basichondrocranium relationships: Abnormalities in experimental axial skeletal (dysraphic) disorders. J Embryol Exp Morphol 53:15-38, 1979

23. Marin-Padilla M, Marin-Padilla TM: Morphogenesis of experimentally induced Arnold--Chiari malformation. J Neurol Sci 50(1):29-55, 1981

24. Markunas CA, Tubbs RS, Moftakhar R, Ashley-Koch AE, Gregory SG, Oakes WJ, Speer MC, Iskandar BJ: Clinical, radiological, and genetic similarities between patients with Chiari Type I and Type 0 malformations. J Neurosurg Pediatr 9(4):372-378, 2012

25. Mavinkurve GG, Sciubba D, Amundson E, Jallo Gl: Familial Chiari type I malformation with syringomyelia in two siblings: Case report and review of the literature. Childs Nerv Syst 21(11):955959 [Epub Apr 9, 2005].

26. McLone DG, Knepper PA: The cause of Chiari II malformation: A unified theory. Pediatr Neurosci 15(1):1-12,1989

27. Milhorat TH, Bolognese PA, Nishikawa M, McDonnell NB, Francomano CA: Syndrome of occipitoatlantoaxial hypermobility, cranial settling, and chiari malformation type I in patients with hereditary disorders of connective tissue. J Neurosurg Spine 7(6):601-609, 2007

28. Milhorat TH, Chou MW, Trinidad EM, Kula RW, Mandell M, Wolpert C, Speer MC: Chiari I malformation redefined: Clinical and radiographic findings for 364 symptomatic patients. Neurosurgery 44(5):1005-1017, 1999

29. Miller JH, Limbrick DD, Callen M, Smyth MD: Spontaneous resolution of Chiari malformation Type I in monozygotic twins. J Neurosurg Pediatr 2(5):317-379,2008

30. Nishikawa M, Sakamoto H, Hakuba A, Nakanishi N, Inoue Y: Pathogenesis of Chiari malformation: A morphometric study of the posterior cranial fossa. J Neurosurg 86(1):40-47, 1997

31. Nyland H, Krogness KG: Size of posterior fossa in Chiari type 1 malformation in adults. Acta Neurochir (Wien) 40(3-4):233-242, 1978

32. Petraglia AL, Chengazi HU, Chung MM, Silberstein HJ: Leber congenital amaurosis associated with Chiari I malformation: Two cases and a review of the literature. Surg Neurol Int 3:4,2012

33. Pillay PK, Awad IA, Little JR, Hahn JF: Symptomatic Chiari malformation in adults: A new classification based on magnetic resonance imaging with clinical and prognostic significance. Neurosurgery 28(5):639-645, 1991

34. Schady W, Metcalfe RA, Butler P: The incidence of craniocervical bony anomalies in the adult Chiari malformation. J Neurol Sci 82(1-3):193-203, 1987

35. Solth A, Barrett C, Holliman D, Mitchell P: Chiari malformation in female monozygotic twins. Br J Neurosurg 24(5):607-608, 2010
36. Speer MC, Enterline DS, Mehltretter L, Hammock P, Joseph J, Dickerson M, Ellenbogen RG, Milhorat TH, Hauser MA, George TM: Chiari type I malformation with or without syringomyelia: Prevalence and genetics. J Genet Couns 12:297-311, 2003

37. Speer MC, George TM, Enterline DS, Franklin A, Wolpert CM, Milhorat TH: A genetic hypothesis for Chiari I malformation with or without syringomyelia. Neurosurg Focus 8(3):E12, 2000

38. Stovner LJ: Headache and Chiari type I malformation: Occurrence in female monozygotic twins and first-degree relatives. Cephalalgia 12(5):304-307; discussion 268, 1992

39. Stovner LJ, Bergan U, Nilsen G, Sjaastad O: Posterior cranial fossa dimensions in the Chiari I malformation: Relation to pathogenesis and clinical presentation. Neuroradiology 35(2):113-118, 1993

40. Stovner LJ, Cappelen J, Nilsen G, Sjaastad O: The Chiari type I malformation in two monozygotic twins and first-degree relatives. Ann Neurol 31(2):220-222, 1992

41. Stovner LJ, Sjaastad O: Segmental hyperhidrosis in two siblings with Chiari type I malformation. Eur Neurol 35(3):149-155, 1995

42. Szewka AJ, Walsh LE, Boaz JC, Carvalho KS, Golomb MR: Chiari in the family: Inheritance of the Chiari I malformation. Pediatr Neurol 34(6):481-485, 2006

43. Tubbs RS, Hill M, Loukas M, Shoja MM, Oakes WJ: Volumetric analysis of the posterior cranial fossa in a family with four generations of the Chiari malformation Type I. J Neurosurg Pediatr 1(1):21-24, 2008

44. Tubbs RS, Wellons JC 3rd, Blount JP, Oakes WJ: Syringomyelia in twin brothers discordant for Chiari I malformation: Case report. J Child Neurol 19(6):459-462, 2004

45. Tubbs RS, Wellons JC 3rd, Oakes WJ: Asymmetry of tonsillar ectopia in Chiari I malformation. Pediatr Neurosurg 37(4):199-202, 2002

46. Turgut M: Chiari type I malformation in two monozygotic twins. $\mathrm{Br}$ J Neurosurg 15(3):279-280, 2001

47. Vega A, Quintana F, Berciano J: Basichondrocranium anomalies in adult Chiari type I malformation: A morphometric study. J Neurol Sci 99(2-3):137-145, 1990

48. Warkany J: Congenital Malformations: Notes and Comments. Chicago: Year Book Medical, 1971: 225

49. Weisfeld-Adams JD, Carter MR, Likeman MJ, Rankin J: Three sisters with Chiari I malformation with and without associated syringomyelia. Pediatr Neurosurg 43(6):533-538, 2007

50. Wolpert CM, Gripp KW, Mu H, Trinidad E, Milhorat T, Speer MC: Familial aggregation of Chiari type malformation in 8 families. Am J Hum Genet 59:A109, 1996

51. Yabe I, Kikuchi S, Tashiro K: Familial syringomyelia: The first Japanese case and review of the literature. Clin Neurol Neurosurg 105(1):69-71, 2002

52. Zakeri A, Glasauer FE, Egnatchik JG: Familial syringomyelia: Case report and review of the literature. Surg Neurol 44(1):48-53, 1995 